\title{
ASSESSMENT OF THE ANTIAGGREGANT EFFECT OF IBUPROFEN IN HEALTHY SUBJECTS: IBU-AGREE STUDY.
}

\author{
Ribera $A^{\prime}$, Llau JV', 2 , Ferrandis $\mathrm{R}^{\mathrm{I}, 3}$. \\ 'University of Valencia ${ }^{2}$ Hospital Clínic of València, ${ }^{3}$ Hospital La Fe of València \\ Spain
}

\section{Objective of the study}

It is well known that the non-steroidal anti-inflammatory agents (NSAIDs) have an antiaggregant effect by inhibiting steps in thromboxane A2 (TxA2)-mediated platelet activation. Until now, this effect has not been fully assessed compared with the antiaggregant effect of aspirin (ASA). The objective of this study is to determine if the administration of an oral standard dose of ibuprofen $(600 \mathrm{mg})$ is able to produce an antiaggregant effect, at least similar than the one produced by the administration of a 100 to $300 \mathrm{mg}$ of ASA (therapeutic range).

\section{Methods}

IBU-Agree is a descriptive study, made in healthy subjects taking a $600 \mathrm{mg}$ table of ibuprofen because of moderate headache. They

had no any haemostasis complication history (Rappaport classical questions were included also to support it). Subjects taking any NSAID or garlic tablets at least three days before

were not included. A sample of $3 \mathrm{ml}$ of whole blood was obtained thorough venous puncture before 180 minutes after

the intake (estimated ibuprofen Tmax is 90'-150').

To assess the antiaggregation power of ibuprofen, we used the specific kit for ASA for the device VerifyNow $®$ (Accumetrics,

$$
\text { Inc., San Diego, CA-USA). }
$$

The results are shown in ARU (Aspirin Reactive Units): >550 ARU means a normal platelet reactivity without dysfunction related with ASA or similar drugs; $<550$ ARU means antiaggregation related with the mechanism of action of ASA.

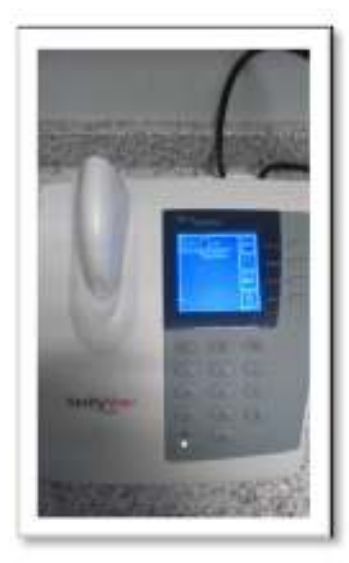

VerifyNow device

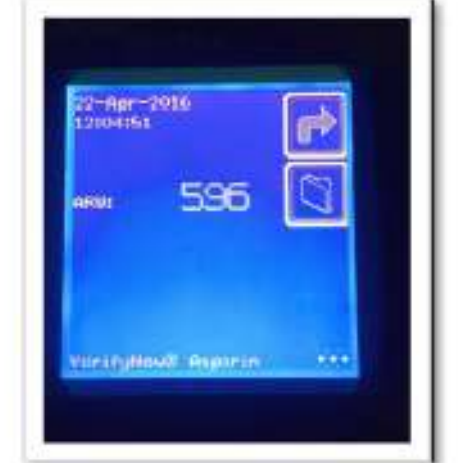

Result of $>550$ ARU is consistent with antiaggregation

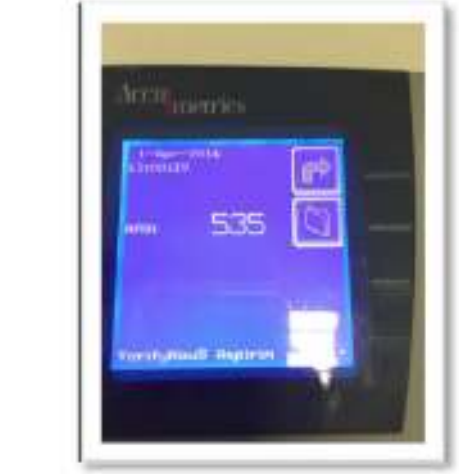

Result of $<550$ ARU is consistent with no antiaggregation

As it is a descriptive study, no statistics is needed.

\section{Results}

I 4 healthy subjects were included (I0 M, 4 F). Age range was 22-54 years and body weight range was 43-89 kg. The samples were obtained between 100' and 165' after the intake of ibuprofen. The results showed that $13 / 14$ subjects were antiaggregated at that time (ARU range $350-490)$ and I/I4 subject was no antiaggregated (ARU 59I).

\begin{tabular}{|c|c|c|c|c|c|c|c|c|c|c|c|c|c|c|}
\hline Time between IBU intake and sample & 140 & 100 & 112 & 120 & 130 & 125 & 125 & 125 & 145 & 152 & 165 & 142 & 145 & 156 \\
\hline ARU results & 350 & 465 & 460 & 350 & 591 & 490 & 438 & 408 & 440 & 419 & 412 & 405 & 467 & 432 \\
\hline
\end{tabular}

\section{Conclusions}

The results of this study show that the intake of $600 \mathrm{mg}$ of ibuprofen induces an antiaggregated state similar to the one after the therapeutic administration of ASA (100-300 $\mathrm{mg}$ ). Although more studies are needed to confirm if this antiaggregated state could be related with a haemorrhage tendency, we could anticipate that patients with haemostatic disturbances or fragile ones should avoid the intake of NSAIDs, mainly in the perioperative period. 